\title{
Design Museums: Making Sense or Sensation of Design
}

Taking the premise that design museums are essentially institutions of knowledge this paper investigates how curatorial practice conveys the meaning and understanding of design. Design, being of a strong visual nature, is often set in scene with great theatrics, but not without consequences to the exhibition's ability to make sense of design. With a case study of Triennale Design Museum in Milan the paper asks what happens to the conveyed meanings when the design exhibition it self is perceived as a design object.

\section{Introduction}

Since the 2007 inauguration of the Triennale Design Museum in Milan, every spring has seen a new edition of the Permanent Collection of Italian Design. Pursuing the mission of constantly reinventing itself the entire museum space is once a year rearranged by a new curator in residence, predominantly a person of prominence in the scene of Italian architecture and design. The curator creates a narrative of personal interest by selecting items from the Permanent Collection and mixing them with items on loan from external collections of art and design, sketches and prototypes and sometimes rather random personal effects. These annual exhibits are known as the Triennale Design Museum Editions abb. TDM1, 2, 3 etc. The exhibition opening kicks off the Salone del Mobile arguably the world's most important trade fair in furniture and product design - and is repeatedly acclaimed by critics as one of the highlights of the Milan Design Week.

The Triennale Design Museum is but one of several to have seen the light of day in the wake of the cult-like status that 'design' attained during the millennium-vicinal decades. Although the role and nature of the designated design museum are under development there seems to be a general consensus that design in this context relates to industrial production since ca. 1900. Consistent with prevailing canons name-designer furniture and consumer products continues to take precedence in both older and new permanent collections but there is a growing emphasis on so called 'anonymous everyday objects' such as packaging, communications and digital design.

Design's move into the museum space has been interpreted as a sign of elevated cultural status because it enters the sphere of fine art (Gimeno-Martínez \& Verlinden 2010). Perhaps more importantly the move signifies the admittance into a knowledge institution with a long and strong tradition for the shaping of public perceptions. Although what defines a museum has become less rigid and elitist in the $21^{\text {st }}$ century what has never changed is its authoritative claim to specialized knowledge in specific subject fields. 
Therefore, what is voiced within design museums, how and by whom, is of no little consequence to the general understanding and appreciation of design.

\section{Curating Design}

The voice of the Triennale Design Museum belongs to designers, architects and manufactures. They are free to make their selection of the objects and personalities to be celebrated in the exhibit. They create their narratives of personal interest in cooperation with a set-designer of their choice. Even if one ignores, at first, the unorthodox risk of vocational nepotism, this curatorial decision seems biased towards a professional if not promoting agenda in leaving the interpretation of design in the hands of the makers. Especially considering that academic design discourse increasingly considers the meaning of design to emanate from a circuit of numerous actants (Julier 2008, Du Gay et al. 1997), counting design (disinterested) consumers amongst them. If design museums are to be recognized as knowledge institutions one can reasonably expect them to also reach out to a design-illiterate audience. How to capture the complex reality and meaning of contemporary design is a challenge that faces curatorial departments everywhere. Museum exhibitions on design has long since been criticized for approaching the matter as though it were art; a default strategy that is likely to be explained by the circumstance that until recently the majority of design curators were art historians by training.

The latest development has seen personalities from the publishing sector of design and architectural criticism take the lead of curatorial departments (MoMA, V\&A, Design Museum London). This has brought about a discursive development in exhibition strategies where the singular design object is less emphasized in and of itself, and instead appears as synecdoche in a greater narrative. In Design Museum London e.g. the exhibitions This is Design (2011/12) and Extraordinary Stories about Ordinary Things (2013/14) have served as a best practice study before the arrangement of the permanent collection in the museum's future Kensington location. Among the narratives tried on for size were 'taste', 'identity', 'material and process', 'lifecycle' and 'manufacture'; in the last mentioned the de rigour parade of iconic $2 \mathrm{O}^{\text {th }}$ century chairs served as a step-by-step illustration of technological and material developments. Every new step was meticulously explained so that novice design audiences may begin to make sense of technology's influence on aesthetics.

\section{Triennale Design Museum}

"One hundred significant objects from contemporary Italy, offered to you in such a manner that museum itself becomes the hundred-and-first object" (TDM1 2009:391)

In the Triennale Design Museum's Edition portfolio sensation seems to be the driving force. Davide Rampello - unintentionally - hits the nail right on the head when he explains how the museum from the start have been "conceding little space to objects and much time to their representation" (TDM3 2010: 23). For there is a difference between context and representation and, when exaggerated, the latter might very well cloud the first. In the $1^{\text {st }}$ Edition curated by Andrea Branzi the exhibition was purposefully created to appear as an object in its own right, thereby presenting no other reality for design than design it self. In the words of set-designers Peter Greenaway and Italo Rota the aim was: 
"(...) to create an auto-reflective exhibition that demonstrates the significance of design objects within the original setting of their own proud planning. The objects must display their pride in existing, given that the human mind requires and relentlessly insist upon novelty. But they must also display their pride in belonging to that famous club of the other design objects, because this signifies solidarity, respect, and continuity with the past" (op cit).

Alessandro Mendini, perhaps even more successfully, deployed the exhibit-as-object strategy in the highly appraised $3^{\text {rd }}$ Edition. Among Mendini's 800 selected objects were a reproduction of a $15^{\text {th }}$ century headgear, a silver medal, and giant versions of a sandal, a Campari bottle and Michelangelo's David. The accompanying curatorial statement appeared as personal diary entries where Mendini reflects on the archaeology of Italian Design. Taking the concept of contemporary design to the very brim, the collected exhibit was celebrated as a masterpiece by other design professionals (Rawsthorn, 2010). And one can easily imagine how Mendini's pickings would appear to the creative mind as an exhilarating giant mood-board. But what is the actual intellectual return of the layman's time invested in a museum exhibit of this kind?

For the $6^{\text {th }}$ Edition, on show in 2013/14, Pierluigi Nicolin pared up a number of Italian name-designers and brands to curate one another for the purpose of investigating the nature and influence of the Italian genius. The result is an exhibition in 3 sections, comprised of individual portrait-installations that may well be seen as design entities themselves. The TDM6 therefore makes for a suitable in-depth case study of how meaning is conveyed when the design museum exhibit is treated as a design object.

The first section of TDM6 is devoted to the "earliest masters", meaning the post WWII vanguard. Here ten contemporary designers interpret the legacy of ten masters in ten very conceptual installations. But in the general absence of these masters' work - there's it literally very few visual examples on display - it becomes unclear in what sense the master geniuses inspired this section.

Blumeandfriends' account for the legacy of Marco Zanuso is an interactive production site, where a step on a foot pedal, activates the noisy backstage process of imprinting aluminium sheets with the word 'ZANUSO'. After a few moments the sheets are fed through an opening on to the stage, into a pile. The happening is accompanied by explosion images shown on Zanuso \& Sapper's 1969 Black television for Brionvega. The installation comments on the possessive consumerist culture of the 1950s' America, which "has become a creepy obsession, perhaps even for Zanuso" (TDM6 2013: p.58). This interpretation of Zanuso seems a bit speculative based on this happening alone. The dubiousness is especially evident in the catalogue that labels Zanuso "a symbol of an era in which the system of artificial production led by industry was the directly referential wonder itself" (op. cit.). In all fairness this applies to most of these modern masters and is hardly a 'rediscovery' of Zanuso's legacy in particular.

Alessandro Scandurra refrains from such vague interpretations and ventures on instead into a highly philosophical account of his work with " $\mathrm{S}$ " (Ettore Sottsass). The catalogue speaks in tongues about "the intimacy of death with life" (Ibid: 98) in the work of "S". The most explanatory paragraph reads:

"S. dressed the death of life. And led the unrepeatable into the space of infinite repetition. For this reason, the walls here are flowering with life, the endless 
theme 2

memory

Figure 1.

Flos showcase by Ron Gilad (TDM6, 2013) Author's Photograph strand 3

design museums

proliferation of sex, the vital gesture, the game in which dearth creates desire, desire creates gesture, and gesture meets with another. Because we are broken vessels, pots always hoping to find the perfect boarder" (op. cit.).

Botanical images and illustrations from the Kama Sutra comprise this room. A projector screen on a scaffold standing next to a pile of broken vases make up a virtual slot machine, that constantly spins images, nine at a time, in figurative themes. This arrangement repetitiously places images of Sottsass' work next to images of architecture, urban landscapes, movie stills, religious icons, pictograms, fine art and the work of other designers; a tour de force of visual culture that any onlooker with the capacity to identify Sottsass' work within a few seconds will no doubt appreciate and immensely enjoy.

Although eminently executed the ten installations resonate the conceptual exercises of students in design and architectural schools. They are the sorts of conceptualizations of the design process that only people with prerequisite knowledge can decipher, since they tend to leave the actual product out. The Bruno Munari installation by Cassani \& Librizzi illustrates this. In an effort to visualize their thesis about a pre-specified position in Munari's work, they created a gym-like environment of ceiling-hung trapezes, hoops and latters. The metaphor in play is the task of hanging a picture on the wall, which is approachable from numerous positions depending on the hook on the frame and the nail in the wall. Even with nothing else in the room the piece probably still makes sense to anyone familiar with Munari's early mobiles and 'useless machines'. But without the proper prerequisite knowledge some allegories are rather bewildering, as in Paolo Ulian's reference to Arne Jacobsen's chair No 7 and Charles Rennie Mackintosh' Hill house chair as some of the "anonymous" everyday objects that inspired Vico Magistretti. In this sense it is quite an esoteric interpretation of design legacy that characterizes section one and so, consequently, when it comes down to grasping the genius of the designer from all of this, it might take one to know one.

In the second section objects seem to enter the stage, but rather than taking the spotlight they merely comprise the "obscure landscape" surrounding a cacophony of video-memoirs. These are the faces and voices of twelve leading figures of the rebellious 1970/80s' anti-design scene - now a gathering of distinguished silver foxes in powersuits - and the "obscurity" of the set is owed to a random arrangement of their (obscure?) signature pieces. Listening to the twelve testimonials and personal career recollections anyone still in doubt becomes painfully aware that design is not at the centre of Italian design in this museum - designers are.

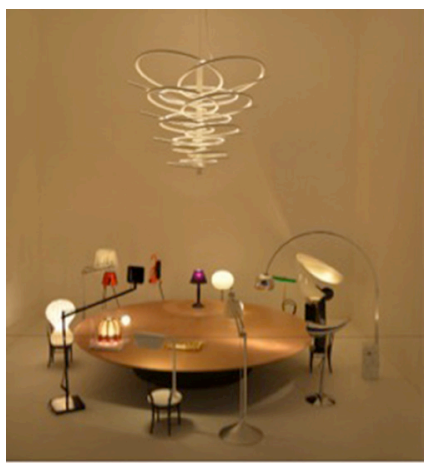


When "things" finally take precedence in the third section they have been so infused with the author-genie that it is impossible to separate one from the other. Inside twelve room-size showcases designer objects are cast as people inhabiting the Imaginarium of twelve designer curators. The most luminous example of the way in which design is here made to personify its creator is in Ron Gilad's Flos Banquet showcase where 15 iconic Flos bestsellers are seated around a table and lit up by Gilad's own 2026 LED Chandelier (Fig. 1). This setting calls to mind the game of "which party of famous people would you most like to have for dinner?" Here we have the honourable Castiglioni brothers, Citterio, Starck, Morrison, Barber \& Osgerby, Grcic and, of cause, Gilad himself.

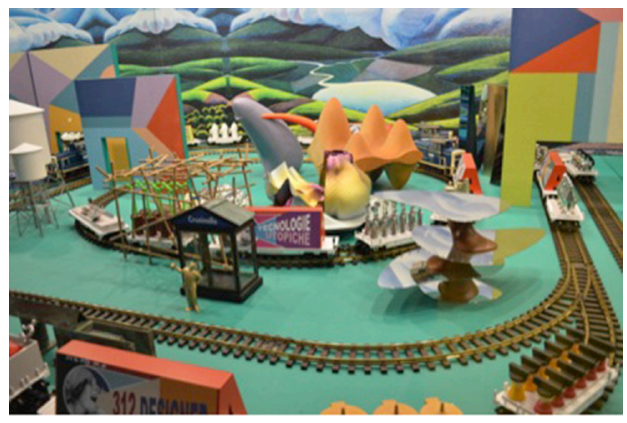

Figure 2.

Alessi Showcase by Alessandro Mendini (TDM6, 2013) Author's photograph

In Mendini's Alessi showcase (Fig. 2) a delegation of miniature toilet brushes, coffee makers and corkscrews are travelling by electric train through a colourful landscape of pots, plates and cake stands. This scenario vividly illustrates V\&A senior curator Kieran Long's point that theatricality can detract from a museum's ability to tell the truth (Long 2013). The applied theatrics in Mendini's "Alessi in wonderland" is so reminiscent of a department store window display at Christmas time that the sudden urge to go shopping quite subdues the possibility of any intellectual reflection. In addition, the miniature versions remove the already less than obvious Alessi household utilities far from any reality of actual use. In this scenario the design objects make no sense - only the Alessi brand does.

It is only all the more concerning when Nicolin identifies the consumer household as the actual testing ground for Italian design's relationship with ways of life. Having first pronounced the represented brands as the key-players in the continuous Italian worldleadership in design, Nicolin states that

"(...) it is the responsibility of pilot-companies to oversee the philosophy of the latest forms of design. Even in the presence of the first signs of rebellion, the brand model still "marks" design objects, guiding purchasing patterns and acting as a guarantee of quality and innovation for the excessive range of products available to consumers" (TDM6 2013: 29).

According to this there is a reality to these choo-choo trains and merry-go-rounds that contains a message of responsibility towards the end consumers. It does, however, take a fair amount of design literacy to distil the philosophy from the fairground. 


\section{Conclusion}

Design exhibitions that are treated as design objects have a strong visual appeal that may well serve to further promote and accumulate design's popularity in society. But as a curatorial strategy the exhibit-as-object is less suitable for digging below the surface of design as mere lifestyle products and for understanding the circuit of factors that makes design a cultural key player today. At best the exhibit-as-object offers a glimpse through the keyhole to the creator's studio. This can certainly be an awe-inspiring experience, not least to other (upcoming) design professionals. But when designers curate meta-design narratives on the intellectual premise of a better-than-average acquaintance with design history and a high level of abstraction in terms of metaphors, they end up addressing mainly their peers. Others may listen and be entertained, but the chances for making sense rather than sensation of design are slim.

\section{References}

du Gay, P., Hall, S., Janes, L., Mackay, H. and Negus, K. (1997) Doing Cultural Studies: The story of the Sony Walkman London, California, New Dehli: Sage Publications

Gimeno-Martínez, J. and Verlinden, J. (2010) 'From museum of decorative arts to design museum: The case of the Design museum Gent', Design and Culture, vol. 2, no. 3,

pp. 259-283.

Julier, G. (2008) The Culture of Design, 2nd edition, London: Sage

Long, K. (2013, Sept. 12) 'Sinister objects demand attention just at much as beneficial ones', Dezeen Magazine, Available: http://www.dezeen.com/2013/og/12/opinion-kieranlong-on-contemporary-museum-curation/ [19 Jan 2014]

Rawsthorn, A. (2010, Aug. 29) 'An Italian Designer's Homage to His Native Country', The New York Times art section.

Triennale Design Museum (TDM) (2007) TDM1: La Sette Ossesione del Design Italiano The Seven Obsessions of Italian Design, Milano: Triennale Design Museum.

Triennale Design Museum (TDM) (2010) TDM3: Quali Cose Siamo The Things We Are. Milano: Triennale Design Museum.

Triennale Design Museum (TDM) (2013) TDM6: La Sindrome dell'Influenza The Syndrome of Influence. Milano: Triennale Design Museum. 